\title{
Management strategies of marine food resources under multiple stressors with particular reference of the Yellow Sea large marine ecosystem
}

\author{
Qisheng TANG (凶) \\ Key Laboratory of Sustainable Development of Marine Fisheries, Ministry of Agriculture; Carbon Sink Fisheries Laboratory, \\ Yellow Sea Fisheries Research Institute, Chinese Academy of Fishery Sciences, Qingdao 266071, China
}

\begin{abstract}
In this study two main management strategies are discussed: one is to develop resource conservationbased capture fisheries, and the other is to develop environmentally friendly aquaculture. During the resource recovery period, the development of environmentally friendly aquaculture should be encouraged, especially in integrated multi-trophic aquaculture, which is adaptive, efficient and sustainable. For future development and better understanding the ecosystem, it is necessary to further strengthen basic research.
\end{abstract}

Keywords marine, ecosystem, management strategies, food resources, Yellow Sea

\section{Introduction}

The coastal ocean ecosystems around the globe encompassing large marine ecosystems (LME), annually produce about $80 \%$ of the world's marine food supply. However, numerous studies have confirmed that the coastal ocean ecosystems and its resources have changed greatly under the multiple stressors, including over-exploitation, pollution and climate change [1-5]. Therefore, in order to promote sustainable development of the ecosystems, the exploration and implementation of effective management strategies is important and urgent task, e.g. ecosystem approach (EA) and ecosystem based management (EBM) $[6,7]$.

The Yellow Sea is a semi-enclosed shelf sea with typical LME characteristics including distinct bathymetry, hydrography, productivity and trophically linked populations [8]. Over the past half a century, the food resources in the

Received April 13, 2014; accepted May 4, 2014

Correspondence: ysfri@public.qd.sd.cn ecosystem have changed greatly, such as significant changes to the structure of the fisheries resulting from unsustainable fisheries, increased threats from both land and sea-based sources of pollution and increased fluctuations in resource populations during climate change [911]. In this paper, the Yellow Sea LME was chosen as an example to discuss the management strategies of marine food resources under multiple stressors. Furthermore, marine food resources include stock resources, genetic resources and product resources (natural products and active substance), which are related to capture fisheries, aquaculture and new bio-industry (marine medicine and biological products) respectively. Since a proactive approach is well underway in an effort to produce more protein from the exploitation of genetic resources, we will focus on the discussion of development of a new production model of aquaculture.

\section{Changing states of the Yellow Sea LME and their causes}

\subsection{Over-exploitation: overfishing}

Since 1980, Yellow Sea fisheries significantly declined in catch-per-unit-effort after fishing efforts greatly increased [10]. Hereafter, the survey data showed that dramatic changes in species composition, dominant species and the community structure of resource populations in the Yellow Sea LME have been observed-from small yellow croaker and hairtail in the 1950s and early 1960s to Pacific herring and chub mackerel in the 1970s, and then to anchovy and sandlance after the 1980s. Small-sized, fast-growing, short-lived and low-valued species increased markedly in abundance during the $1980 \mathrm{~s}$ assuming a prominent position in ecosystem resources and the food web. Recent surveys indicate that the abundance of pelagic species 
such as anchovy is declining, while the biomass of demersal species such as small yellow croaker is increasing $[12,13]$.

\subsection{Pollution}

Serious eutrophication and nutrient structure changes in the Yellow Sea LME are 'fertilizing' coastal areas triggering red tides, green tide, jellyfish bloom and oxygen deficiencies $[14,15]$. The harmful algal blooms and low levels of dissolved oxygen (dead zones) in the water make it difficult for fish, benthic fauna and other marine creatures to survive, and for related social and economic activities to be sustainable. Since the 1970 s, the annual mean water temperature and level of dissolved nitrogen in the sea increased by $1.7^{\circ} \mathrm{C}$ and $2.95 \mu \mathrm{mol} \cdot \mathrm{L}^{-1}$, respectively, while dissolved oxygen, phosphorus, and silicon decreased by $59.1,0.1$ and $3.93 \mu \mathrm{mol} \cdot \mathrm{L}^{-1}$, respectively [16]. As a result, the frequency of occurrence of harmful algal blooms has gradually increased, and the size of hypoxic areas (where dissolved oxygen is $\leqslant 2 \mathrm{mg} \cdot \mathrm{L}^{-1}$ ) [17] is on the rise in coastal waters. These events affect the most productive areas of the marine environment and lead to the destruction of important habitats needed to maintain ecosystem health.

\subsection{Climate impacts}

Generally speaking, climate change may have important effects on the recruitment of pelagic species and shellfish. Pacific herring in the Yellow Sea has a long history of extreme variability and corresponding exploitation. In the last century, the commercial fishery experienced three peaks (1900, 1938 and 1972), followed by periods of little or no catch. Good relationship between the fluctuations in herring abundance of the Yellow Sea and the 36-year cycle of wetness oscillation in eastern China has been documented $[18,19]$. A new study identifies four SST (sea surface temperature) regimes in the Yellow Sea LME over the past 141 years: a warm regime before 1900, a cold regime from 1901 to 1944 , a warm regime with a cooling trend from 1945 to 1976, and a warm regime with a warming trend from 1977 to 2007 [20]. During the period of 1982 through 2006, sea surface temperature of the Yellow Sea LME increased by $0.67^{\circ} \mathrm{C}$ [21]. SST regime shifts and fluctuations in herring abundance show a strong correlation. Since 2005, both herring stocks and eelgrass biomass (where herring spawn), have increased in Sanggou Bay-a former major herring spawning ground and now a large scale mariculture area. However, the recovery is incomplete. At the same time, several unusual events have occurred recently in coastal areas. A false killer whale visited Qingdao Bay, an event that had not been observed for over 30 years. On 18 January 2008, a sperm whale landed on Herring Beach in Sanggou Bay. This was the first time local people saw a species this large (body length, $19.6 \mathrm{~m}$; weight, $51.1 \mathrm{t}$ ). The regime shifts in the Yellow Sea LME are likely to have important effects on ecosystem resources in other areas of the North Pacific Ocean.

\subsection{Control mechanism}

Changes in state have been a basic feature in the coastal ocean ecosystems, especially in the Yellow Sea LME under multiple stressors. An analysis of inter-decadal variations of ecosystem production indicates that it is difficult to use any established theory (e.g., bottom-up control, or top-down control or wasp-waist control) to directly and clearly explain the long term variations of the productivity of different trophic levels in the coastal ocean ecosystems [22]. For example, under the same fishing pressure, the biomass yields of some exploited stocks in the Yellow Sea appear to be fairly stable (e.g., Spanish mackerel) or recovered (e.g., small yellow croaker), while changes in population resources and species shifts in dominance cannot be explained merely by fishing pressure. We propose that there may be two types of shifts in ecosystem resources: systematic replacement and ecological replacement. Systematic replacement occurs when one dominant species declines in abundance or is depleted by overexploitation, and another competitive species uses the surplus food and vacant space to increase its abundance. Ecological replacement occurs when minor changes in the natural environment affect stock abundance, especially pelagic species. In the long-term, the effects of the two types of shifts (or multi-stressors) on the ecosystem and its resources may be intermingled. Therefore, an acceptable explanation is that the apparently dynamic characteristics of the productivity in the coastal ocean ecosystem may be a consequence of multifactorial controls. The multi-control mechanism may contribute to ecosystem complexity and uncertainty. When we face the impacts of multi-stressors and multi-control mechanisms, the best option is to develop an adaptive strategy for the practice of ecosystem-based management (EBM).

\section{Management strategies and sustainability}

\subsection{Adaptive management strategies under multiple stressors}

EBM simply means taking a place-based, ecosystem approach to management, with the goal of sustaining the long-term capacity of the system to deliver ecosystem services $[23,24]$. In the case of Yellow Sea LME as mention above, in order to recover resources, reduce environmental stress and produce more protein for food security, two main management strategies should be 
encouraged. One is to develop resource conservationbased capture fisheries and the other is to develop environmentally friendly aquaculture.

\subsubsection{Development of resource conservation-based capture fisheries}

There are many ways to recover resources in a stressed LME. The main mitigation and recovery practices include reducing excessive fishing mortality, controlling point sources of pollution, and gaining a better understanding of the effects of natural perturbations. After 1995, China closed fishing in the Yellow Sea and East China Sea LMEs for two to three months in the summer. This fishing ban has effectively protected juvenile fish, leading to an increase in the quantity and quality of fish catches. In addition to these efforts, artificial enhancement in the Yellow Sea LME has been conducted. Since 1984, the experimental release of penaeid shrimps in the Bohai Sea, the north Yellow Sea and the southern waters off the Shandong Peninsula has achieved remarkable social and economic benefits. In 2006, the Chinese State Council promulgated a program of action on the conservation of living aquatic resources of China [25]. This program has provided guidance for the conservation of living aquatic resources, and plainly called for increasing fishery stock enhancement. Since then, stock enhancement has become a public activity for increasing marine food resources in China, and about 50 billion hatchlings of several species were put into the Chinese coastal waters from 2006 to 2010. Therefore, artificial enhancement practices are an effective resource recovery strategy that should be expanded to a LME scale. But, as we know, the recovery of ecosystem resources is a slow and complex process, so the development of resource conservation-based capture fisheries will be a long-term and arduous task.

\subsubsection{Development of environmentally friendly aquaculture}

During the resource recovery period, one best way is to develop aquaculture to produce more fish protein for human needs while minimizing pollution. Studies of the ecosystem dynamics of the Yellow Sea have provided some new scientific knowledge for developing a new mariculture production model as detailed below.

There is a negative relationship between ecological conversion efficiency of resource species and trophic level at the higher trophic levels of the ecosystem [26]. This new finding indicates that the ecological efficiency could increase when fishing down marine food webs at lower trophic levels and ecosystem resources will be increased. Based on this finding, a new harvest strategy according to different requirements should be considered. If we are concerned with large fish, (1) harvest species at high trophic levels, or top harvest strategy will be selected; if we need more seafood, (2) harvest species at low trophic levels or non-top harvest strategy, will be selected. In China, the latest 5-year average annual production of mariculture exceeds $15 \mathrm{Mt}$, and the production of shellfish and seaweeds represents about $85 \%$ of this total. Clearly B, the selection of lower trophic levels, and the development of a new mariculture production model will be a good choice.

Shellfish and seaweed mariculture increase atmospheric $\mathrm{CO}_{2}$ absorption by coastal ecosystems [27]. This study showed that through mariculture of shellfish and seaweeds, it is estimated that $3.79 \pm 0.37 \mathrm{Mt} \mathrm{C} \cdot \mathrm{yr}^{-1}$ are being utilized, and $1.20 \pm 0.11 \mathrm{Mt} \mathrm{C} \cdot \mathrm{yr}^{-1}$ were removed from the coastal ecosystem by harvesting from 1999 to 2008 . The result illustrates that cultivated shellfish and seaweeds can indirectly and directly take up a significant volume of coastal ocean carbon. Shellfish accomplish this by removing phytoplankton and particulate organic matter through filter feeding, while seaweeds utilize carbon through photosynthesis. Thus, mariculture of seaweeds and shellfish plays an important role in carbon fixation, and therefore contributes to improving the capacity of coastal ecosystems to absorb atmospheric $\mathrm{CO}_{2}$. This new finding encouraged us to develop environmentally friendly aquaculture, and the new production model is called integrated multi-trophic aquaculture (IMTA).

\subsection{Sustainable production model: Innovative IMTA}

Not only does IMTA provide more production but it also indirectly or directly reduces excess atmospheric $\mathrm{CO}_{2}$ and nutrients, and increases the social acceptability of culturing systems.

\subsubsection{Mode of IMTA}

The various modes of IMTA are implemented effectively in Sanggou Bay within the Yellow Sea LME. They include IMTA of long-line culture of abalone and kelp, IMTA of long-line culture of finfish, bivalves and seaweed, and IMTA of benthic culture of abalone, sea cucumber, clam and seaweed $[28,29]$. An important criterion in constructing these production modes is to get good ecological benefits. For example, in an IMTA system for finfish, bivalves and seaweeds, kelp and Gracilaria lemaneiformis can be used to remove and transform dissolved inorganic nutrients from the effluent of both finfish and bivalves. It can also provide dissolved oxygen to the finfish and bivalves. In addition, oysters and sea urchins will filter the suspended particulate organic materials from the fish feces, residual feed, and phytoplankton.

\subsubsection{Carbon budget of IMTA}

The carbon budget in an IMTA system of kelp, abalone and 


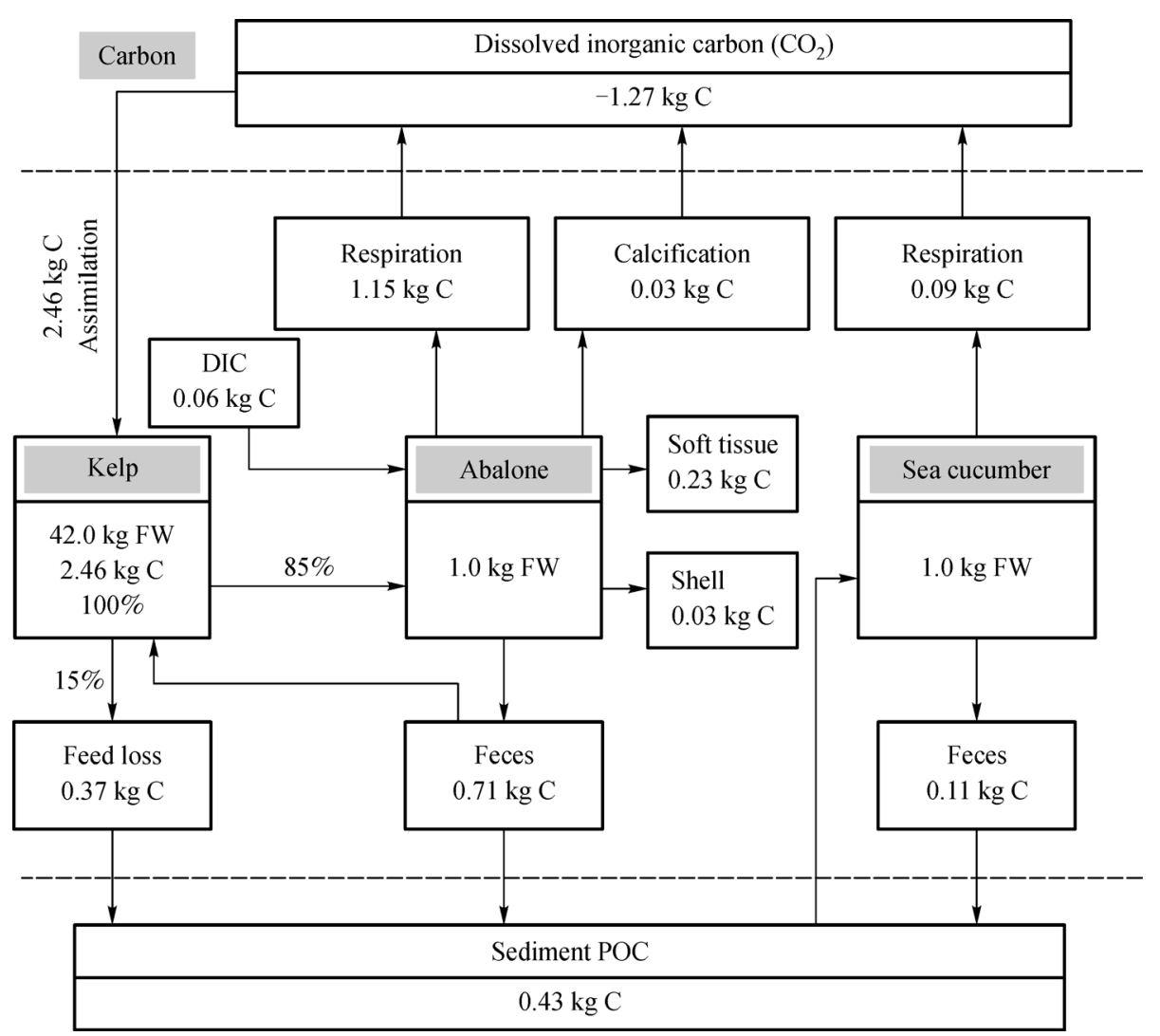

Fig. 1 Carbon budget in an integrated multi-trophic aquaculture system of kelp, abalone and sea cucumber during a farming cycle

sea cucumber during a farming cycle of about 900 days (from seeding to harvest) is shown in Fig. 1. When $1 \mathrm{~kg}$ of abalone (fresh weight with shell) is harvested, the total ingested carbon is $2.15 \mathrm{~kg}$ (kelp is the food source), where $12 \%$ is utilized for soft tissue and shell growth, 55\% for respiration and calcification, $33 \%$ for feces. In the farming cycle, bio-deposited particulate organic carbon from feces and feed lost is $1.08 \mathrm{~kg}$, where $69 \%$ is used as food sources of sea cucumber, and $21 \%$ sinks to the bottom. While this system provides $52 \%$ of the dissolved inorganic carbon for kelp photosynthesis, which is mainly produced by respiration and the calcification process of abalone and sea cucumber. Obviously, nutrition in this system is efficiently used on an ecosystem level, and the application of the IMTA mode can remove a significant amount of carbon from sea.

\subsubsection{Ecosystem services value of IMTA}

Using the systemic evaluation approach, the value of the mariculture ecosystem services on four different modes in the Sanggou Bay, including the kelp monoculture mode, scallop monoculture mode, abalone-kelp IMTA mode, and kelp-abalone-sea cucumber IMTA mode, were estimated and evaluated. The value of food provision service and climate regulating service in different mariculture modes is shown in Table 1 The value of the ecosystem services

Table 1 Service function of different mariculture modes including monocultures and integrated multi-trophic aquaculture (IMTA) systems

\begin{tabular}{lcc}
\hline Mariculture mode & $\begin{array}{c}\text { Value of food provision service } \\
/\left(\mathrm{CNY} \cdot \mathrm{hm}^{-2} \cdot \mathrm{yr}^{-1}\right)\end{array}$ & $\begin{array}{c}\text { Value of climate regulating service } \\
/\left(\mathrm{CNY} \cdot \mathrm{hm}^{-2} \cdot \mathrm{yr}^{-1}\right)\end{array}$ \\
\hline Kelp monoculture & 49219 & 4859 \\
Abalone monoculture & 235409 & 8215 \\
Abalone and kelp IMTA & 325553 & 13591 \\
Abalone, sea cucumber and kelp IMTA & 483918 & 13833 \\
\hline
\end{tabular}

Note: The data are based on the 17 major value parameters and methods by Costanza et al. [30]. The core services of the mariculture ecosystem in Sanggou Bay were selected and quantified through a market value, carbon tax and shadow project approaches [31]. 
provided by the IMTA mode is much higher than in a monoculture

\section{Concluding remarks}

The above analysis shows that the coastal ocean ecosystems can change greatly under multiple stressors, including over-exploitation and utilization, both land and sea-based sources of pollution, and climate change including global warming and natural fluctuations, as represented in the Yellow Sea LME. It is mainly manifested in the changes of biodiversity and productivity of ecosystem resources, and as a result, larger, higher trophic level and commercially important demersal species were replaced by smaller, lower trophic level, pelagic, lessvaluable species. The analysis indicates that coastal ocean ecosystems can be controlled by multiple factors leading to complexity and uncertainty of ecosystem changes that are difficult to identify and manage.

The above results demonstrate that two main management strategies of food resources of marine ecosystem under multiple stressors are practicable; one for stock resources (capture fisheries) and the other for genetic resources (aquaculture). During the resource recovery period, development of environmentally friendly aquaculture is to be encouraged, especially in IMTA. The various modes of IMTA provide not only a food provision service but also a climate regulating service. IMTA is an adaptive, efficient, and sustainable way to respond to multiple stressors for coastal ocean ecosystems.

Also it is clear that basic research is important. In fact, the main scientific basis of two management strategies comes from the studies of ecosystem dynamics of the Yellow Sea LME, e.g., Key Processes and Sustainable Mechanisms of Ecosystem Food Production in the Coastal Ocean of China [32] and Sustainability of Marine Ecosystem Production under Multi-stressors and Adaptive Management [33]. For future development and better understanding of coastal ecosystems, it is necessary to further strengthen basic research. A comprehensive process-oriented study of ecosystem service and goods functions needs to be given special attention, including the biology and regional ecology of resource species and culture species, and the biogeochemical cycling and hydrodynamic processes of coastal ecosystems. Moreover, studies on the functions and processes of carbon sink/ source and the impact of ocean acidification on ecosystem resources should be further examined. This will increase the managing and predictive capability of ecosystem managers.

Acknowledgements I would like to thank the Major Consulting Projects of Chinese Academy of Engineering and the National Key Basic Research Development Plan of China for supporting this study. Thanks to Jianguang FANG, Jihong ZHANG, Zengjie JIANG and Hongmei LIU for their valuable help during preparation of the manuscript. Thanks to a number of anonymous reviewers for their valuable comments.

Compliance with ethics guidelines Qisheng Tang declare that he has no conflict of interest or finemcial conflicts to disclose

This article does not contain any studies with human or animal subjects performed by the author.

\section{References}

1. Sherman K, Alexander L M, Gold B D, eds. Large Marine Ecosystems: Stress, Mitigation, and Sustainability. Washington, DC: AAAS Press, 1993, 376

2. Garcia S M, Newton C. Current situation, trends, and prospects in world capture fisheries. In: Piktch EL, Huppert DD, Sissenwine MP, eds. Global trends: fisheries management. Bethesda, Maryland, American Fisheries Society Symposium, 1997, 20: 3-27

3. Harris R and the members of the GLOBEC Scientific Steering Committee (SSC). Global Ocean Ecosystem Dynamics (GLOBEC): Science P1an. IGBP Report 40 (GLOBEC Report 9). Stockholm, Sweden: IGBP Secretariat, 1997, 83

4. UNEP. Marine and coastal ecosystems and human wellbeing: a synthesis report based on the findings of the millennium ecosystem assessment. UNEP, 2006, 76

5. Sherman K, McGovern G. Frontline observations on climate change and sustainability of large marine ecosystems. Large Marine Ecosystems 17, 2012 United Nations Development Program, 203

6. Pikitch E K, Santora C, Babcock E A, Bakun A, Bonfil R, Conover D O, Dayton P, Doukakis P, Fluharty D, Heneman B, Houde E D, Link J, Livingston P A, Mangel M, McAllister M K, Pope J, Sainsbury K J. Ecosystem-based fishery management. Science, 2004, 305(5682): 346-347

7. Browman H U, Stergioug K I. Politics and socio-economics of ecosystem-based management of marine resources. Marine Ecology Progress Series, 2005, 300: 241-296

8. Sherman K. Large marine ecosystems as global units for marine resources management - an ecological perspective. In: Sherman K, Alexander LM, Gold BD, eds. Large Marine Ecosystems: Stress, Mitigation, and Sustainability. Washington, DC: AAAS Press, 1993, 79-83

9. Tang Q S. Changes in the biomass of the Yellow Sea ecosystem. In: Sherman K, Alexander LM, eds. Biomass Yields and Geography of Large Marine Ecosystem. AAAS Selected Symposium 111. Boulder, CO: Westview Press, 1989, 7-35

10. Tang Q S. Effects of long-term physical and biological perturbations on the contemporary biomass yields of the Yellow Sea ecosystem. In: Sherman K, Alexander LM, Gold BD, eds. Large Marine Ecosystems: Stress, Mitigation, and Sustainability. Washington, DC: AAAS Press, 1993, 79-83

11. Zhang C I, Kim S A. Living marine resources of the Yellow Sea ecosystem in Korean waters: status and perspectives. In: K. Sherman and Q. Tang, eds. Large Marine Ecosystems of the Pacific Rim. Cambridge, MA: Blackwell Science, 1999, 163-178

12. Tang Q S, Fang J G. Review of climate change effects in the Yellow Sea large marine ecosystem and adaptive actions in ecosystem based management. In: Sherman K, McGovern G, eds. Frontline 
Observations on Climate Change and Sustainability of Large Marine Ecosystem. Large Marine Ecosystem, 2012, 17: 170-187

13. Jin X S. Small yellow croaker. In: Tang QS, ed. Living Marine Resources and Inhabiting Environment in the Chinese EEZ. Science Press, Beijing, 2006, 1130-1133(in Chinese)

14. UNDP/GEF Present status of marine pollution. In: The Yellow Sea: Analysis of Environment Status and Trends, Volume 3: Regional Synthesis Reports. UNDP/GEF Yellow Sea Project, 2007, 163-208

15. Zhu Z Y, Zhang J, Wu Y, Zhang Y Y, Lin J, Liu S M. Hypoxia off the Changjiang (Yangtze River) Estuary: Oxygen depletion and organic matter decomposition. Marine Chemistry, 2011, 125(1-4): $108-116$

16. Lin C L, Ning X R, Su J L, Lin Y, Xu B. Environmental changes and the responses of the ecosystems of the Yellow Sea during 19762000. Journal of Marine Systems, 2005, 55(3-4): 223-234

17. Li D J, Zhang J, Huang D J, Wu Y, Liang J. Oxygen depletion off Changjiang (Yangze Reiver) Estuary. Science in China (series D), 2002, 45(12): 1137-1146

18. Tang Q S. A preliminary study on the causes of fluctuations on year class size of Pacific herring in the Yellow Sea. Transactions of Oceanology and Limnology, 1981, 2: 37-45 (in Chinese)

19. Tang Q S. Yellow Sea Herring. In: Hay et al., eds. Herring Expectations for a New Millennium. Alaska Sea Grant College program, 2002, 389-391, 436-437

20. Huang D J, Ni X B, Tang Q S, Zhu X H, Xu D F. Spatial and temporal variability of sea surface temperature in the Yellow Sea and East China Sea over the past 141 years. In: Shih-Yu Wang ed. Modern Climatology, ISBN: 978-953-51-0095-9, In Tech, 2012, 213-234

21. Belkin I. Rapid warming of large marine ecosystem. Progress in Oceanography, 2009, 81(1-4): 207-213

22. Tang Q S, Jin X S, Wang J, Zhuang Z M, Cui Y, Meng T X. Decadal-scale variation of ecosystem productivity and control mechanisms in the Bohai Sea. Fisheries Oceanography, 2003, 12 (4-5): 223-233

23. Rosenberg A A, McLeod K I. Implementing ecosystem-based approach to management for the conservation of ecosystem services. Marine Ecology Progress Series, 2005, 300: 270-274
24. McLeod K I, Lubcheco J. "Scientific Consensus Statement on Marine Ecosystem-Based Mangement. Signed by 221 academic scientists and policy experts with relevant expertise" Communication Partnership for Science and the Sea. Available at Compassonline website in 2014

25. Chinese State Council. Program of action on the conservation of living aquatic resources of China. 2006, 1-18 (in Chinese)

26. Tang QS, Guo XW, Sun Y, Zhang B. Ecological conversion efficiency and its influencers in twelve species of fish in the Yellow Sea Ecosystem. Journal of Marine Systems, 2007. 67: 282-291

27. Tang Q S, Zhang J H, Fang J G. Shellfish and seaweed mariculture increase atmospheric $\mathrm{CO}_{2}$ absorption by coastal ecosystems. Marine Ecology Progress Series, 2011, 424: 97-105

28. Fang J G, Funderud J, Zhang J H, Jiang Z J, Qi Z H, Wang W. Integrated multi-trophic aquaculture (IMTA) of sea cucumber, abalone and kelp in Sanggou Bay, China. In: Walton MEM, ed. Yellow Sea Large Marine Ecosystem Second Regional Mariculture Conference. UNDP-GEF project "Reducing environmental stress in the Yellow Sea Large Marine Ecosystem”. Jeju, Republic of Korea, 2009

29. Tang Q S, Fang J G, Zhang J H, Jiang Z J, Liu H M. Impacts of multiple stressors on coastal ocean ecosystems and integrated multitrophic aquaculture. Progress in Fishery Sciences, 2013, 34(1): 111 (in Chinese)

30. Costanza R, d'Arge R, de Groot R, Farber S, Grasso M, Hannon B, Limburg K, Naeem S, O’Neill R V, Paruelo J, Raskin R G, Sutton P, van den Belt M. The value of the world's ecosystem services and natural capital. Nature, 1997, 387(6630): 253-260

31. Liu H M, Qi Z H, Zhang J H, Mao Y Z, Fang J G. Ecosystem service and value evaluation of different aquaculture mode in Sungo Bay. Qingdao: China Ocean University Press, 2013, 176 (in Chinese)

32. Tang Q S, Su J L, Zhang J. Key processes and sustainable mechanisms of ecosystem food production in the coastal ocean of China. Advances in Earth Sciences, 2005, 20(12): 1281-1287 (in Chinese)

33. Zhang J. Anthropogenic forcings and climate change in the Northern Pacific Region. 5th China-Japan-Korea IMBER Sympo-sium and Training, Shanghai, China, 2011 